\title{
Bicycle Choice Modeling: A Study Of University Trips In A Small Colombian City
}

Orozco Fontalvo, Mauricio Jose; Arevalo Tamara, Andrea Stefannia; Guerrero Barbosa, Thomas Edison; Gutierrez Torres, Margareth Giovanna.

\begin{abstract}
Bicycles and public transportation are modes of sustainable transport that reduce both the increasing levels of pollution and traffic congestion and the worrying statistics concerning obesity and physical inactivity. This article shows results of the application of a stated preferences survey in the city of Ocaña, Colombia, to identify factors that influence the modal choice, introducing the bicycle as an alternative for the trips to and from the University Francisco de Paula Santander Ocaña, using discrete choice models. These results show that the infrastructure availability is a key variable for modal shift and that giving incentives such as meals do not influence modal choice. These results were shared with the local authorities as an argument towards cycle lanes investment and public transportation grants for students.
\end{abstract}

\section{Keywords}

Active Commuting; Bicycle; Discrete Choice; Modal Shift; Multinomial Logit;

Sustainable Transport 